\title{
Coupled Development of Salt Glands, Stomata, and Pavement Cells in Limonium bicolor
}

\author{
Yaru Gao, Boqing Zhao, Xiangmei Jiao, Min Chen, Baoshan Wang* and Fang Yuan* \\ Shandong Provincial Key Laboratory of Plant Stress, College of Life Sciences, Shandong Normal University, Jinan, China
}

OPEN ACCESS

Edited by:

Heng Zhang,

Shanghai Center for Plant Stress

Biology, Shanghai Institute

for Biological Sciences, Chinese Academy of Sciences (CAS), China

Reviewed by:

Weiqiang Li,

RIKEN, Japan

Mariana Reginato,

National University of Río Cuarto,

Argentina

*Correspondence:

Baoshan Wang

bswang@sdnu.edu.cn

Fang Yuan

yuanfang@sdnu.edu.cn

Specialty section:

This article was submitted to

Plant Abiotic Stress,

a section of the journal

Frontiers in Plant Science

Received: 22 July 2021 Accepted: 19 November 2021 Published: 09 December 2021

Citation:

Gao Y, Zhao B, Jiao X, Chen M, Wang $B$ and Yuan $F$ (2021) Coupled

Development of Salt Glands,

Stomata, and Pavement Cells

in Limonium bicolor.

Front. Plant Sci. 12:745422.

doi: $10.3389 / \mathrm{fp} / \mathrm{s} .2021 .745422$
Salt-resistant plants have different mechanisms to limit the deleterious effects of high salt in soil; for example, recretohalophytes secrete salt from unique structures called salt glands. Salt glands are the first differentiated epidermal structure of the recretohalophyte sea lavender (Limonium bicolor), followed by stomata and pavement cells. While salt glands and stomata develop prior to leaf expansion, it is not clear whether these steps are connected. Here, we explored the effects of the five phytohormones salicylic acid, brassinolide, methyl jasmonate, gibberellic acid, and abscisic acid on the development of the first expanded leaf of $L$. bicolor and its potential connection to salt gland, stomata, and pavement cell differentiation. We calculated the total number of salt glands, stomata, and pavement cells, as well as leaf area and pavement cell area, and assessed the correlations between these parameters. We detected strong and positive correlations between salt gland number and pavement cell area, between stomatal number and pavement cell area, and between salt gland number and stomatal number. We observed evidence of coupling between the development of salt glands, stomata, and pavement cells in L. bicolor, which lays the foundation for further investigation of the mechanism behind salt gland development.

Keywords: leaf area, Limonium bicolor, pavement cell, phytohormone, salt gland, stomata

\section{INTRODUCTION}

About $10 \%$ of arable land is affected by salinization worldwide, of which $2.5 \times 10^{9} \mathrm{hm}^{2}$ is irrigated (Ruan et al., 2010). This salinity severely affects plant growth and development and crop yields, especially for countries located in arid and semiarid climate zones (Rozema and Flowers, 2008). Saline land accounts for $4.9 \%$ (or $3.6 \times 10^{7} \mathrm{hm}^{2}$ ) of China's arable land (Li J. et al., 2014). In recent years, the growth of the world population has placed great pressure on global food supply chains, including agricultural productivity. However, unreasonable irrigation and improper application of chemical fertilizers has resulted in secondary salinization of the soil, which is becoming increasingly problematic and in need of a long-term solution (Rengasamy, 2006). Approaches to fundamentally solve the problem of soil salinization have attracted much attention recently.

Most crops cannot survive or complete their life cycle when growing in saline soil (Fan, 2020), while halophytes, representing about $1 \%$ of the plant kingdom, can resistant high salt conditions and produce much biomass under appropriate $\mathrm{NaCl}$ concentrations (Flowers and Colmer, 2008). Halophytes are defined as plants that can survive and complete their life cycle at $\mathrm{NaCl}$ concentrations of $200 \mathrm{mM}$ or above (Flowers and Colmer, 2008). Halophytes provide excellent 

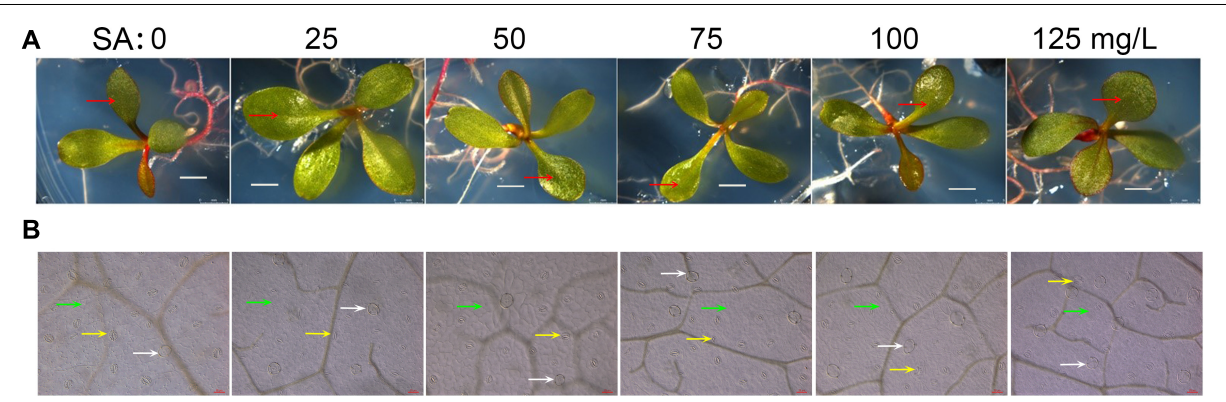

C

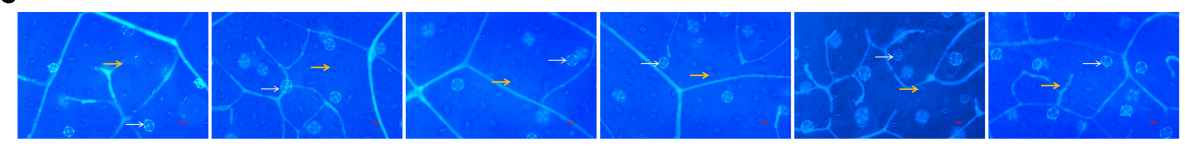

D

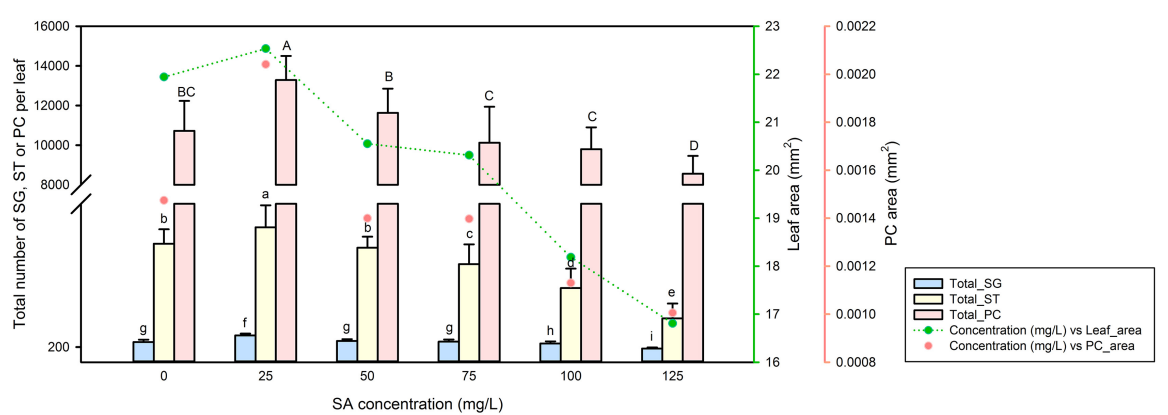

FIGURE 1 | Representative phenotypes of Limonium bicolor seedlings exposed to various concentrations of salicylic acid (SA) for 15 days. (A) Phenotype of L. bicolor treated with different concentrations of SA for 15 days. Red arrows indicate the first expanded true leaf. (B) Representative leaf surface images using an upright microscope. Bar $=25 \mu \mathrm{m}$. White arrows, salt glands; yellow arrows, stomata; green arrows, pavement cells. (C) Visualization of salt glands and stomata by autofluorescence under ultraviolet light. Bar $=25 \mu \mathrm{m}$. White arrows, salt glands; yellow arrows, stomata. (D) Mean numbers of salt glands, stomata, and pavement cells, and total area of expanded leaf and pavement cells as a function of SA concentration. Green line, leaf area; red circles, pavement cell area. Data are shown as means $\pm \mathrm{SD}(n=15)$. Different letters indicate significant differences at $P<0.05$ using Duncan's multiple test. SG, salt gland; ST, stoma; PC, pavement cell.

models to study salt resistance, which could lead to new methods of mitigating soil salinization and increasing crop yield using transgenic techniques (Shabala, 2013; Yuan et al., 2016a).

Under salt stress conditions, halophytes adjust their physiology and biochemistry to reduce or alleviate the damage caused by high salinity (Hasanuzzaman et al., 2014). Halophytes can be classified into three categories based on their mechanism of resistance to high salinity: euhalophytes, pseudo-halophytes and recretohalophytes (Breckle, 1995). Recretohalophytes have unique salt secretory structures called salt glands, their most significant morphological and structural characteristics (Yuan et al., 2015). These salt glands can eliminate excessive salt ions from plant tissues, as seen in the recretohalophyte sea lavender (Limonium bicolor). Similarly, salt cedar (Tamarix chinensis) homogenizes salt concentrations between the surface and deeper layers of saline soil through salt glands (Feng et al., 2018). Sea milkwort (Lysimachia maritima, previously called Glaux maritima L.) also avoids high concentrations of $\mathrm{Na}^{+}$and $\mathrm{Cl}^{-}$ ions in its tissues via salt glands (Rozema and Riphagen, 1977).

Given their importance in conferring salt resistance, the evolutionary origin and gene expression profile of salt glands have garnered substantial interest (Dassanayake and Larkin, 2017). Salt gland development has been studied in Limonium vulgare (Thomson, 1975). Salt glands arise from five consecutive cell divisions of a single epidermal cell to form a gland complex composed of 20 cells (Wiehe and Breckle, 1990). About 67 species distributed among 13 families possess salt glands (Yuan and Wang, 2020), but few have been investigated in details. L. bicolor is a typical recretohalophyte with salt glands on its leaf epidermis. It is considered a model halophyte to study salt gland development (Yuan et al., 2016a) due to the ease with which structures can be observed by autofluorescence and to a high-efficiency transformation system (Yuan et al., 2014). Each L. bicolor salt gland consists of 16 cells: four secretory cells, four accessory cells, four inner cup cells, and four outer cup cells (Yuan et al., 2016a). The continuous observation of leaf development revealed five typical developmental stages, starting with an undifferentiated stage, followed by the salt gland differentiation stage, stomatal differentiation stage, and pavement cell differentiation stage, and ending with the mature stage (Yuan et al., 2015).

Salt glands are therefore considered to be the first differentiated structure of the epidermis, and their numbers increase with leaf expansion (Leng et al., 2018), suggesting a possible relationship between salt glands and pavement cells along the expanding leaf. There is evidence that various treatments affect the number of salt glands and leaf area in a similar direction. For instance, calcium ions $\left(\mathrm{Ca}^{2+}\right)$ 

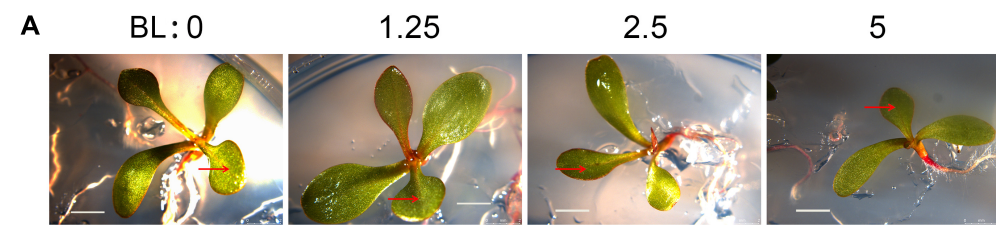
$7.5 \mathrm{mg} / \mathrm{L}$

B
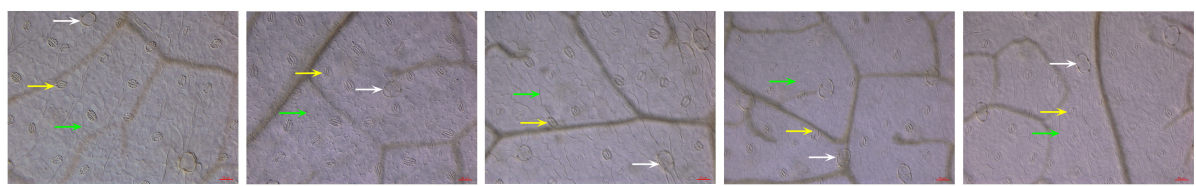

C
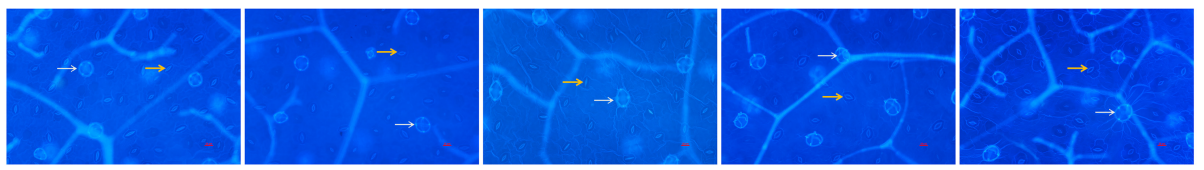

D

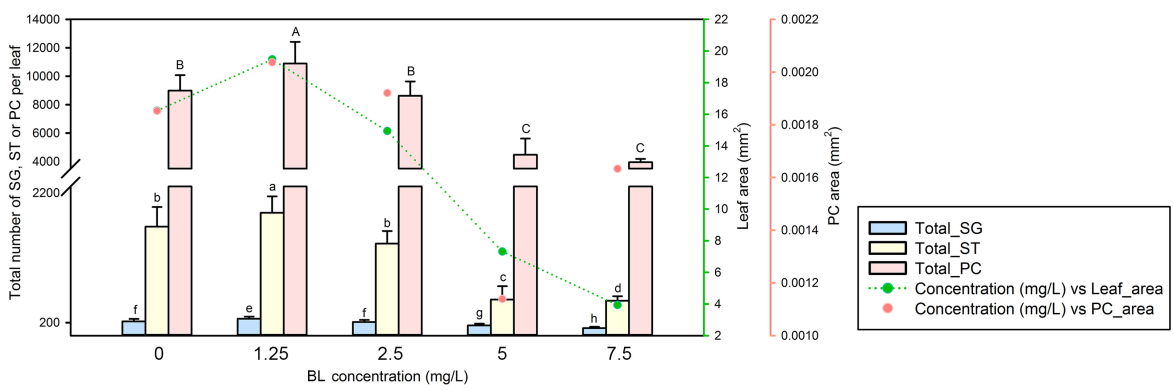

FIGURE 2 | Representative phenotypes of L. bicolor seedlings exposed to various concentrations of brassinolide (BL) for 15 days. (A) Phenotype of L. bicolor treated with different concentrations of $\mathrm{BL}$ for 15 days. Red arrows indicate the first expanded true leaf. (B) Representative leaf surface images using an upright microscope. Bar = $25 \mu \mathrm{m}$. White arrows, salt glands; yellow arrows, stomata; green arrows, pavement cells. (C) Visualization of salt glands and stomata by autofluorescence under ultraviolet light. Bar $=25 \mu \mathrm{m}$. White arrows, salt glands; yellow arrows, stomata. (D) Mean numbers of salt glands, stomata, and pavement cells, and total area of expanded leaf and pavement cells as a function of BL concentration. Green line, leaf area; red circles, pavement cell area. Data are shown as means $\pm \mathrm{SD}(n=15)$. Different letters indicate significant differences at $P<0.05$ using Duncan's multiple test. SG, salt gland; ST, stoma; PC, pavement cell.

(Ding et al., 2010), $\mathrm{NaCl}$ (Yuan et al., 2018) and exogenous nitric oxide (NO) (Ding, 2013) can promote the development of salt glands and increase total leaf area in L. bicolor. However, a systematic exploration of the possible relationship between salt glands, stomata, and pavement cells is lacking. Here, we applied five phytohormones known to influence salt gland development to investigate the potential links between epidermal cell types.

Phytohormones are small organic molecules that play a key role in plant metabolism, growth, and development at very low concentrations (Shi et al., 2017). When plants are subjected to various environmental stresses (such as salt stress), plant hormones also sustain continuous growth and development by balancing endogenous signals and exogenous stress (Yu et al., 2020). Methyl jasmonate (MeJA) can improve the resistance of $L$. bicolor to high salt conditions (Yuan et al., 2018). Melatonin has a similar effect by repressing the biosynthesis of abscisic acid (ABA) under high salinity, thus promoting seed germination and increasing the number of salt glands (Li et al., 2019, 2020). However, previous reports mainly employed exogenous treatment of large seedlings by spraying phytohormone solutions grown in soil or Hoagland's nutrient solution, and none involved the direct addition of phytohormones to the growth medium to follow changes in leaf area or the number of salt glands, epidermal cells, or stomata. Here, five phytohormones [salicylic acid (SA), brassinolide (BL), MeJA, gibberellic acid $\left(\mathrm{GA}_{3}\right)$ and $\mathrm{ABA}$ ] were separately added in the media to investigate their effect on the differentiation and number of salt glands, stomata, and pavement cells from the first true expanded leaf to explore the possible relationships between salt glands, stomata, pavement cells, and leaf development.

\section{MATERIALS AND METHODS}

\section{Plant Materials}

Seeds of L. bicolor were collected in October 2019 from the inland saline soil of the Yellow River Delta (N37 $20^{\prime}$; E118 $\left.36^{\prime}\right)$ in Dongying, Shandong, China. Uniform seeds were selected for sowing after storage at $4^{\circ} \mathrm{C}$ for 6 months.

\section{Phytohormone Treatments}

The seeds of L. bicolor were initially surface-sterilized in 75\% ethanol for $5 \mathrm{~min}$, followed by soaking in $6 \%$ sodium hypochlorite 


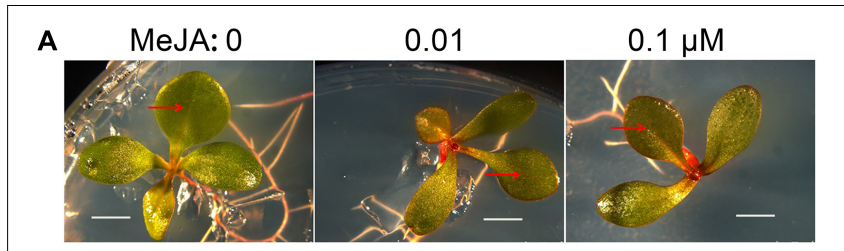

B

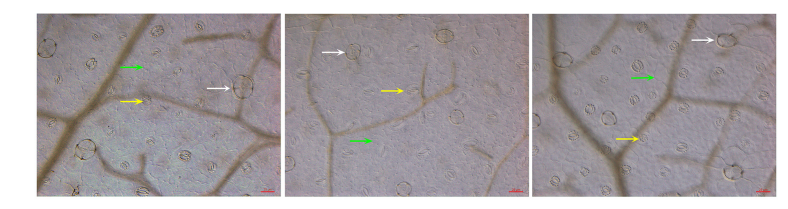

C

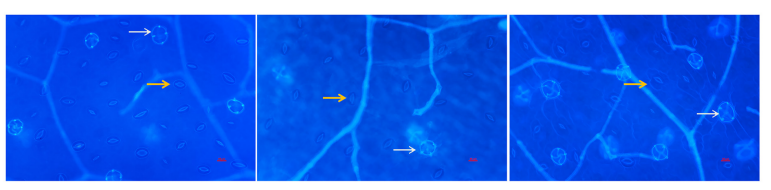

D

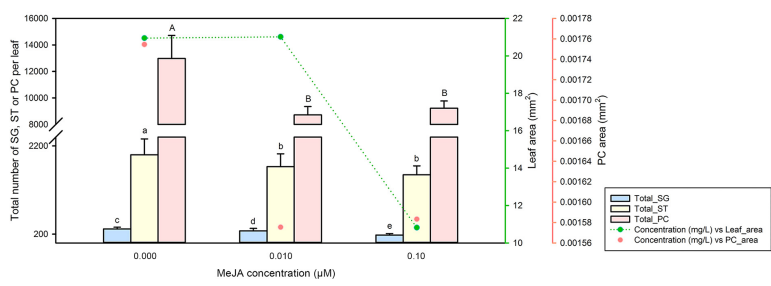

FIGURE 3 | Representative phenotypes of $L$. bicolor seedlings exposed to various concentrations of methyl jasmonate (MeJA) for 15 days.

(A) Phenotype of $L$. bicolor treated with different concentrations of MeJA for 15 days. Red arrows indicate the first expanded true leaf. (B) Representative leaf surface images using an upright microscope. Bar $=25 \mu \mathrm{m}$. White arrows, salt glands; yellow arrows, stomata; green arrows, pavement cells.

(C) Visualization of salt glands and stomata by autofluorescence under ultraviolet light. Bar $=25 \mu \mathrm{m}$. White arrows, salt glands; yellow arrows, stomata. (D) Mean numbers of salt glands, stomata, and pavement cells, and total area of expanded leaf and pavement cells as a function of MeJA concentration. Green line, leaf area; red circles, pavement cell area. Data are shown as means $\pm \mathrm{SD}(n=15)$. Different letters indicate significant differences at $P<0.05$ using Duncan's multiple test. SG, salt gland; ST, stoma; PC, pavement cell.

solution with shaking for 15-20 min. Seeds were then washed using sterile water three to five times. The seeds were sown on growth medium containing various phytohormones and grown at $26 / 22^{\circ} \mathrm{C}$ (day/night) with a photoperiod of $16 / 8 \mathrm{~h}$ (day/night) and a light intensity of $600 \mu \mathrm{mol} / \mathrm{m}^{2} / \mathrm{s}$.

All seeds were sown on Murashige and Skoog (MS) basal growth medium adjusted to $\mathrm{pH}$ 5.8-6.0 (Murashige and Skoog, 1962). The stock solutions of phytohormones were $50 \mathrm{mg} / \mathrm{mL} \mathrm{SA}$, $0.5 \mathrm{mg} / \mathrm{mL} \mathrm{BL}, 10 \mu \mathrm{M}$ MeJA, $0.1 \mathrm{mg} / \mathrm{mL} \mathrm{GA}_{3}$, and $0.1 \mathrm{mg} / \mathrm{mL}$ ABA. MeJA was dissolved in absolute ethanol, while all other phytohormones were first dissolved in a small volume of absolute ethanol until full dissolution before the volume was adjusted with water. All stock solutions were filtered using a $0.2-\mu \mathrm{m}$ filter.

Salicylic acid was added to MS medium to final concentrations of 25, 50, 75, 100, or $125 \mathrm{mg} / \mathrm{L}$ (Rajjou et al., 2006; Rivas-San Vicente and Plasencia, 2011). BL was added to MS medium at concentrations of 1.25, 2.5, 5, or $7.5 \mathrm{mg} / \mathrm{L}$ (Vogler et al., 2014). MeJA was added to a final concentration of 0.01 or 0.1 MM (Bazabakana et al., 1999; Chen et al., 2012). GA 3 was added to a final concentration of $0.02,0.04,0.06,0.08$, or $0.1 \mathrm{mg} / \mathrm{L}$ (Li G. et al., 2014). ABA was added to a final concentration of $0.02,0.04,0.06$, or $0.08 \mathrm{mg} / \mathrm{L}$ (Pan et al., 2020). Three replicates were sown for each concentration, and each replicate consisted of 20 seeds.

\section{Scoring the Numbers of Salt Glands, Stomata, and Pavement Cells, Leaf Area, and Pavement Cell Area}

After growth for 15 days, the first true leaves were collected and fixed in a mixture of ethanol and acetic acid $(3: 1, \mathrm{v} / \mathrm{v})$, then cleared in $70 \%$ ethanol, before being mounted in Hoyer's solution (Meinke, and David, 1994). The leaves were observed by differential interference contrast (DIC) microscopy (ECLIPSE 80i, Nikon, Tokyo, Japan) with 330-380 nm ultraviolet (UV) excitation Images from five different fields were taken for each leaf, with 15 leaves per treatment. The average numbers of salt glands, pavement cells and stomata were calculated across the five fields using images acquired with a CCD camera (Nikon, Japan). Leaf area and pavement cell area were measured using ImageJ.

Salt gland density was calculated using the number of salt glands in a field, divided by the field area. The total number of salt glands was calculated as leaf area $\times$ salt gland density. Pavement cell density was calculated as the number of pavement cells in a field, divided by the field area, while the total number of epidermal cells was defined as leaf area $\times$ epidermal cell density. Stomatal density was calculated as the number of stomata in a field, divided by the field area, with the total number of stomata being leaf area $\times$ stomatal density.

In parallel, leaves were observed on an upright microscope (DM6B, Leica, Germany) to visualize pavement cells with a $19-\mathrm{mm}$ field of view sCMOS camera with the LAS $\mathrm{X}$ Navigator Software.

\section{Data Analysis}

SPSS (IBM, SPSS Statistics 25) was used for statistical analysis. Duncan's multiple comparisons were performed to determine significant differences between samples, with a significance cutoff of $P<0.05$. Analysis of variance (ANOVA) was used to determine statistical significance. All data collected from the five phytohormone treatments were normalized in SPSS to remove the influence of dimensions. These normalized values were saved as variables and used for correlation analysis according to the phytohormone. Statistical significance was determined by twotailed Student's $t$-test for $P<0.05$ and $P<0.01$.

\section{RESULTS}

\section{The Development of Salt Glands Is Promoted Below 25 mg/L Salicylic Acid}

We first germinated $L$. bicolor seeds on MS medium containing a range of SA concentrations $(0-125 \mathrm{mg} / \mathrm{L})$ to investigate the 


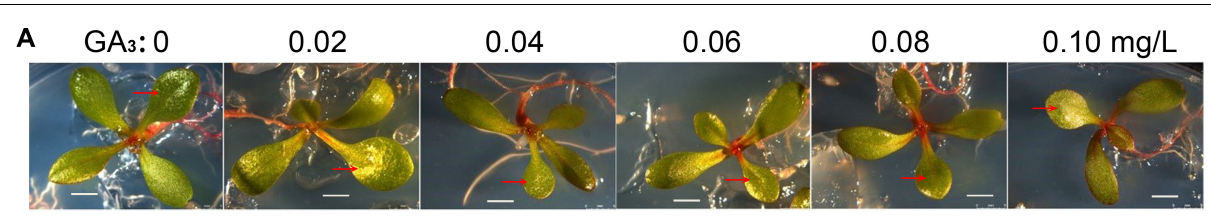

B

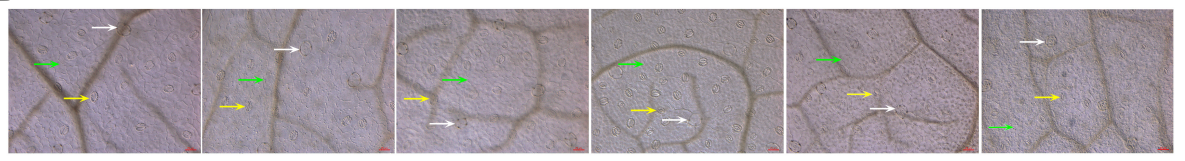

C

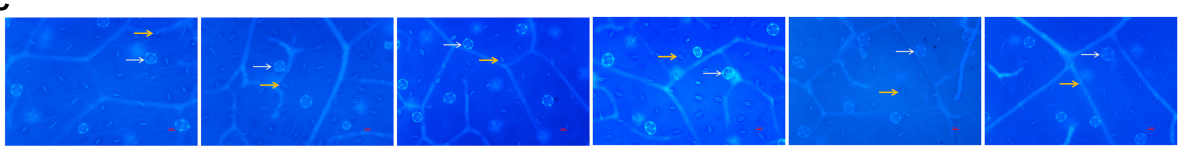

D

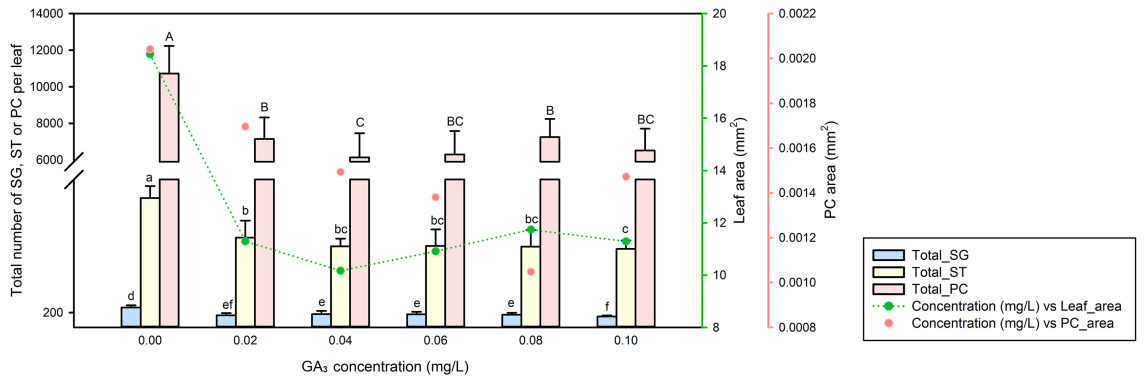

FIGURE 4 | Representative phenotypes of $L$. bicolor seedlings exposed to various concentrations of gibberellic acid (GA 3 ) for 15 days. (A) Phenotype of $L$. bicolor treated with different concentrations of $\mathrm{GA}_{3}$ for 15 days. Red arrows indicate the first expanded true leaf. (B) Representative leaf surface images using an upright microscope. Bar $=25 \mu \mathrm{m}$. White arrows, salt glands; yellow arrows, stomata; green arrows, pavement cells. (C) Visualization of salt glands and stomata by autofluorescence under ultraviolet light. Bar $=25 \mu \mathrm{m}$. White arrows, salt glands; yellow arrows, stomata. (D) Mean numbers of salt glands, stomata, and pavement cells, and total area of expanded leaf and pavement cells as a function of $\mathrm{GA}_{3}$ concentration. Green line, leaf area; red circles, pavement cell area. Data are shown as means $\pm \mathrm{SD}(n=15)$. Different letters indicate significant differences at $P<0.05$ using Duncan's multiple test. SG, salt gland; ST, stoma; PC, pavement cell.

development of salt glands, stomata, and pavement cells from the fully expanded first true leaf (Figure 1A). We measured the area of the epidermis occupied by pavement cells with an upright microscope (Figure 1B) and scored the number of salt glands and stomata using autofluorescence resulting from UV excitation between 330 and $380 \mathrm{~nm}$ (Figure 1C). Given that salt gland density varied under different treatments (Supplementary Figure 1) due to the different leaf area, the total salt gland number on the first true leaf are further used to be compared with stomata and pavement cells.

The area of the first true leaf increased slightly when treated with $25 \mathrm{mg} / \mathrm{L}$ SA relative to control leaves but then decreased with higher SA concentrations (>25 mg/L) (Figure 1D). We observed the same trend for the leaf area covered by pavement cells, which was highest at $25 \mathrm{mg} / \mathrm{L} \mathrm{SA}$. Likewise, the number of salt glands, stomata, and pavement cells followed the same pattern, with the greatest cell numbers obtained with $25 \mathrm{mg} / \mathrm{L} \mathrm{SA}$, and fewer cells at higher SA concentrations ( $>25 \mathrm{mg} / \mathrm{L}$ ) (Figure 1D).

\section{Leaf Development of Limonium bicolor Is Promoted at $1.25 \mathrm{mg} / \mathrm{L}$ Brassinolide}

We next germinated $L$. bicolor seeds and followed seedling growth on MS medium containing 0-7.5 mg/L BL (Figure 2A).
As with SA, we observed pavement cells (Figure 2B), salt glands, and stomata (Figure 2C). Again, leaf area and pavement cell area reached their highest values at the lowest phytohormone concentration (here $1.25 \mathrm{mg} / \mathrm{L} \mathrm{BL}$ ) (Figure 2D), both exhibiting a gradual decrease at higher concentrations $(>1.25 \mathrm{mg} / \mathrm{L})$ of BL. The total numbers of salt glands, stomata, and pavement cells followed similar trends with BL concentration (Figure 2D), peaking at $1.25 \mathrm{mg} / \mathrm{L} \mathrm{BL}$, before dropping with higher $\mathrm{BL}$ concentrations $(>1.25 \mathrm{mg} / \mathrm{L})$.

\section{Methyl Jasmonate Inhibits Leaf Development in Limonium bicolor}

Minute amounts of MeJA can substantially affect leaf development, as evidenced by the inhibition of seedling growth we observed with $0.1 \mu \mathrm{M}$ MeJA (Figure 3A). Accordingly, we determined the developmental status of salt glands, stomata, and pavement cells at low MeJA concentrations of 0.01 and $0.1 \mu \mathrm{M}$ (Figures 3B,C). Leaf area was markedly smaller upon treatment with $0.1 \mu \mathrm{M}$ MeJA but not with $0.01 \mu \mathrm{M}$ MeJA, while pavement cell area already diminished at MeJA concentrations as low as $0.01 \mu \mathrm{M}$ compared to control seedlings (Figure 3D). Similarly, increasing MeJA concentrations were accompanied 

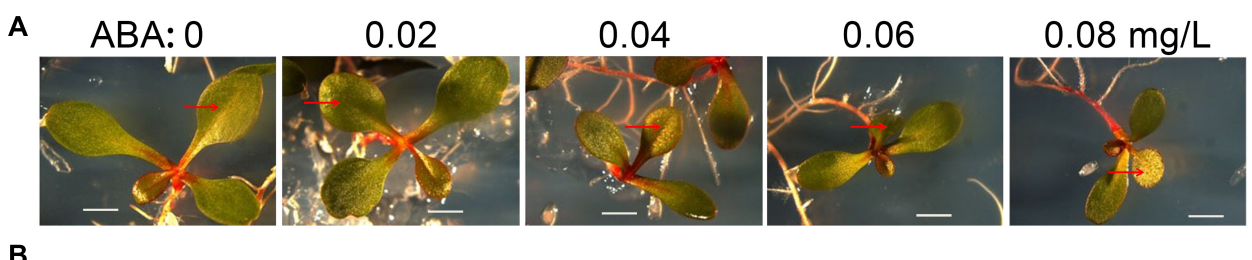

B

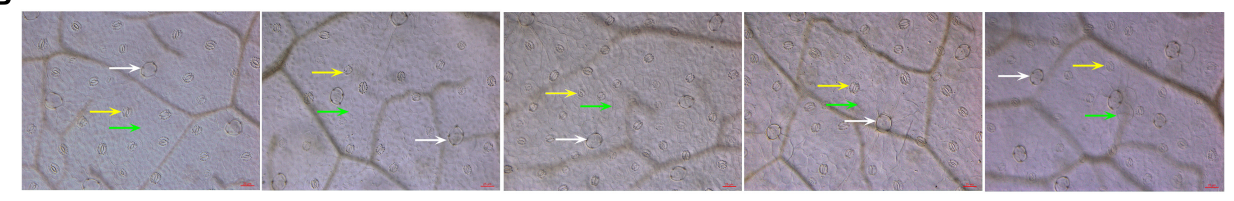

C

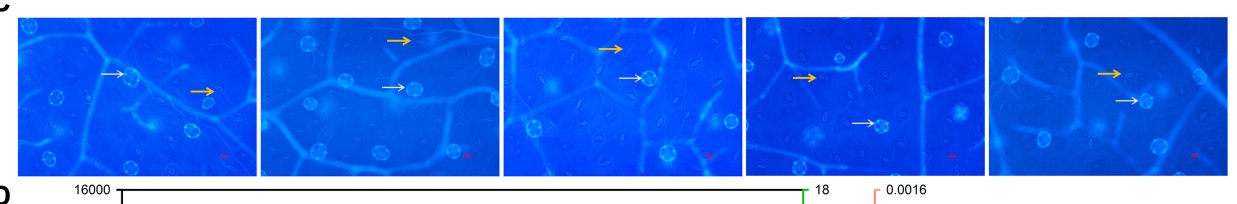

D

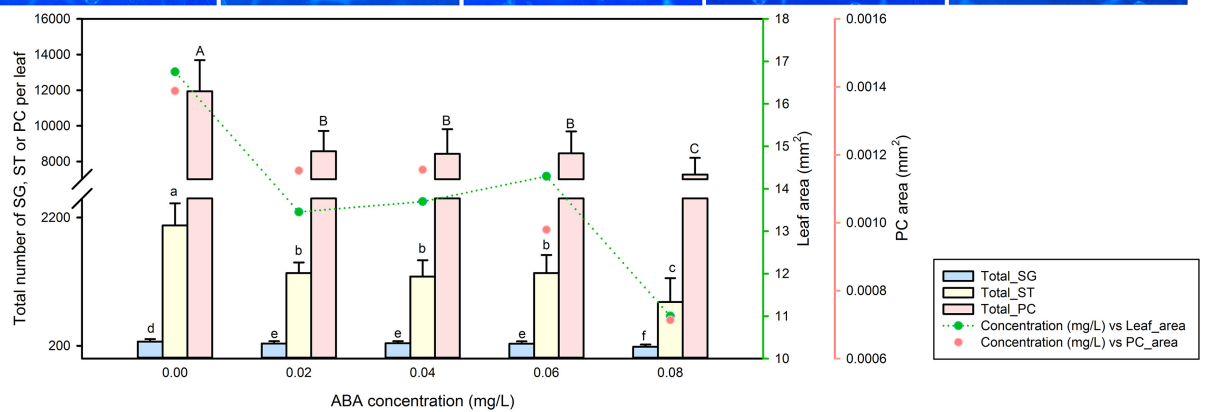

FIGURE 5 | Representative phenotypes of $L$. bicolor seedlings exposed to various concentrations of abscisic acid (ABA) for 15 days. (A) Phenotype of $L$. bicolor treated with different concentrations of ABA for 15 days. Red arrows indicate the first expanded true leaf. (B) Representative leaf surface images using an upright microscope. Bar $=25 \mu \mathrm{m}$. White arrows, salt glands; yellow arrows, stomata; green arrows, pavement cells. (C) Visualization of salt glands and stomata by autofluorescence under ultraviolet light. Bar $=25 \mu \mathrm{m}$. White arrows, salt glands; yellow arrows, stomata. (D) Mean number of salt glands, stomata, and pavement cells, and total area of expanded leaf and pavement cells as a function of ABA concentration. Green line, leaf area; red circles, pavement cell area. Data are shown as means $\pm \mathrm{SD}(n=15)$. Different letters indicate significant differences at $P<0.05$ using Duncan's multiple test. SG, salt gland; ST, stoma; PC, pavement cell.

by a reduction in the total numbers of salt glands, stomata, and pavement cells relative to control conditions.

\section{Gibberellic Acid Treatment Inhibits Leaf Development in Limonium bicolor}

We exposed seeds to five different $\mathrm{GA}_{3}$ concentrations ranging from 0.02 to $0.1 \mathrm{mg} / \mathrm{L}$ (along with a control not treated with $\mathrm{GA}_{3}$ ) and characterized leaf development (Figure 4A), pavement cell expansion (Figure 4B), and the numbers of salt glands and stomata (Figure 4C). Even the lowest $\mathrm{GA}_{3}$ concentration of $0.02 \mathrm{mg} / \mathrm{L}$ limited leaf expansion; raising $\mathrm{GA}_{3}$ concentrations to $0.1 \mathrm{mg} / \mathrm{L}$ did not substantially further reduce leaf area. Pavement cell area showed a similar trend (Figure 4D). Likewise, the numbers of salt glands, stomata, and pavement cells dropped with $0.02 \mathrm{mg} / \mathrm{L} \mathrm{GA} 3$, but then remained constant with higher $\mathrm{GA}_{3}$ concentrations (>0.02 mg/L) (Figure 4D).

\section{Leaf Development of Limonium bicolor Is Suppressed by Abscisic Acid}

Finally, we tested the effects of ABA treatment on leaf growth (Figure 5A) and epidermis development (Figures 5B,C). Low and intermediate ABA concentrations $(0.02-0.06 \mathrm{mg} / \mathrm{L})$ reduced leaf and pavement cell areas to roughly the same extent (Figure 5D). However, the highest ABA concentration applied $(0.08 \mathrm{mg} / \mathrm{L})$ further reduced both leaf and pavement cell areas. The total numbers of salt glands, stomata, and pavement cells displayed the same trends as leaf area (Figure 5D).

\section{Correlation Between Total Numbers of Salt Glands, Stomata, and Pavement Cells; Leaf Area; and Pavement Cell Area Under Different Treatments}

We then explored the correlations between the total numbers of salt glands, stomata, and pavement cells; leaf area; and pavement cell area for each phytohormone using SPSS. For SA treatments, the total salt gland number showed a significant $(P=0.01)$ and positive correlation with leaf area, pavement cell area, total stomatal number, and pavement cell number (Supplementary Table 1). We also obtained strong, positive correlations between stomatal number and leaf area, as well as stomatal number and pavement cell number, indicating that the development of 
TABLE 1 | Correlation analysis between total salt glands (Total_SG) and the other four parameters: total stomata (Total_ST), total pavement cells (Total_PC), leaf area (Leaf_area), and pavement cell area (PC_Area) upon treatment with the five phytohormones salicylic acid (SA), brassinolide (BL), methyl jasmonate (MeJA), gibberellic acid (GA), and abscisic acid (ABA) using Pearson's correlation analysis.

\begin{tabular}{|c|c|c|c|c|c|c|c|}
\hline & Mean & Std. D & Total_SG & Total_ST & Total_PC & Leaf_Area & PC_Area \\
\hline \multicolumn{8}{|c|}{ Correlations } \\
\hline Total_SG & $2.317 \mathrm{E}+02$ & $6.780 E+01$ & 1.000 & & & & \\
\hline Total_ST & $1.348 E+03$ & $4.930 E+02$ & $0.515^{\star \star}$ & 1.000 & & & \\
\hline Total_PC & $9.001 E+03$ & $2.670 E+03$ & $0.609^{\star \star}$ & $0.634^{\star \star}$ & 1.000 & & \\
\hline Leaf_Area & $1.508 \mathrm{E}+01$ & $4.934 E+00$ & $0.682^{\star \star}$ & $0.503^{\star \star}$ & $0.655^{\star \star}$ & 1.000 & \\
\hline PC_Area & 1.483E-03 & 4.321E-04 & $0.264^{\star \star}$ & $0.419^{\star \star}$ & $0.285^{\star \star}$ & $0.189^{\star \star}$ & 1.000 \\
\hline
\end{tabular}

${ }^{* *}$ Correlation is significant at the 0.01 level (2-tailed).

salt glands, stomata, and pavement cells might be coupled or coordinated during leaf expansion.

We then applied the same analysis to the other four phytohormones (Supplementary Tables 2-5). We observed similar results, supporting the notion that the number of salt glands is highly correlated with all other parameters tested. We therefore conclude that larger leaves will present more salt glands, stomata, and pavement cells.

Finally, we integrated the data from all five phytohormones after normalization to remove any scaling effects and repeated the correlation analysis between the total numbers of salt glands, stomata, and pavement cells; leaf area; and pavement cell area (Table 1). Again, we obtained highly significant and positive correlations between salt glands and other parameters.

\section{DISCUSSION}

Leaf development is controlled by a complex regulatory network. Salt glands are a specific derived epidermal structure of recretohalophytes, but how the salt gland differentiate from single epidermal cell is still unclear. Here, we conducted visual assessments and quantifications of the numbers of salt glands, stomata, and pavement cells as well as leaf and pavement cell areas in seedlings exposed to five phytohormones to explore possible relationships during leaf development. All parameters were strongly and positively correlated for all phytohormones tested.

Salicylic acid is an endogenous defense phytohormone that regulates many aspects of plant growth and development, especially during stress responses (Klessig et al., 2018) by reducing the accumulation of reactive oxygen species (ROS; Ma et al., 2017). Exogenous SA treatment can promote germination of Arabidopsis (Arabidopsis thaliana) seeds exposed to high salinity (Lee et al., 2010). Here, in L. bicolor, we added SA to the growth medium to observe its effects on the development of salt glands, stomata, and pavement cells.

When plants are exposed to salt stress, brassinosteroids can result in hormonal stress dose-dependent biphasic effects. Increasing BL levels or enhancing BL signals can increase plant resistance to salt (Liu et al., 2020). Treatment with exogenous BL improves the salt tolerance of perennial ryegrass (Lolium perenne L.) by increasing the activity of antioxidant enzymes and proline content (Wu et al., 2017). Similar to previous studies (Asami et al., 2005), low concentrations of BL (1.25 mg/L) promoted leaf development in L. bicolor in this study, as well as development of salt glands, stomata, and pavement cells. With higher BL concentrations $(>2.5 \mathrm{mg} / \mathrm{L})$, we observed a typical inhibition response for leaf development, which is also consistent with a previous report that high $\mathrm{BL}$ concentrations inhibit the seedling development in Arabidopsis (Bao et al., 2004).

The phytohormones MeJA, GA 3 , and ABA limited leaf development and salt gland differentiation (Yuan et al., 2016b, 2018). As a key phytohormone in plant defenses against pathogenic microorganisms and pests (Yuan et al., 2018), JA increases the transcription of genes encoding antioxidant enzymes in wheat (Triticum aestivum) seedlings, thereby improving their tolerance to salt stress (Qiu et al., 2014). However, in the current results, MeJA added to the growth medium inhibited leaf development of L. bicolor. We obtained similar inhibitory effects with $\mathrm{GA}_{3}$ treatments. $\mathrm{GA}_{3}$ is a growthpromoting plant hormone (Verma et al., 2016) that relieves seed dormancy, promotes stem elongation (Daviere and Achard, 2013), and reduces ROS contents during abiotic stress conditions (Colebrook et al., 2014). A rare role was also reported for $\mathrm{GA}_{3}$ in the development of epidermal structures. Low $\mathrm{GA}_{3}$ concentrations $(0.02 \mathrm{mg} / \mathrm{L})$ inhibited leaf development and the expansion of all leaf structures. Similar results were seen in seedlings treated with the stress phytohormone ABA, which responds to salt stress by regulating stomatal movements, increasing intracellular $\mathrm{Ca}^{2+}$ concentrations, and increasing ROS levels (Yu et al., 2020). In Arabidopsis, ABA sensitivity is typically reduced to improve tolerance to abiotic stress (Xu et al., 2020). We noted the repression of salt gland and stomatal development upon exposure to ABA. While ABA can induce stomatal closure (Postiglione and Muday, 2020), our present results reveal for the first time a relationship between stomatal development and ABA treatment.

\section{Total Salt Gland Number Versus Pavement Cell Number}

As different phytohormones have different effects on leaf development, we combined all normalized data to determine the overall correlation between leaf development parameters. We detected strong correlations between salt gland number and pavement cell area, and between salt gland number and leaf area when considering each phytohormone separately (Supplementary Tables 1-5) or in combination (Table 1). In 


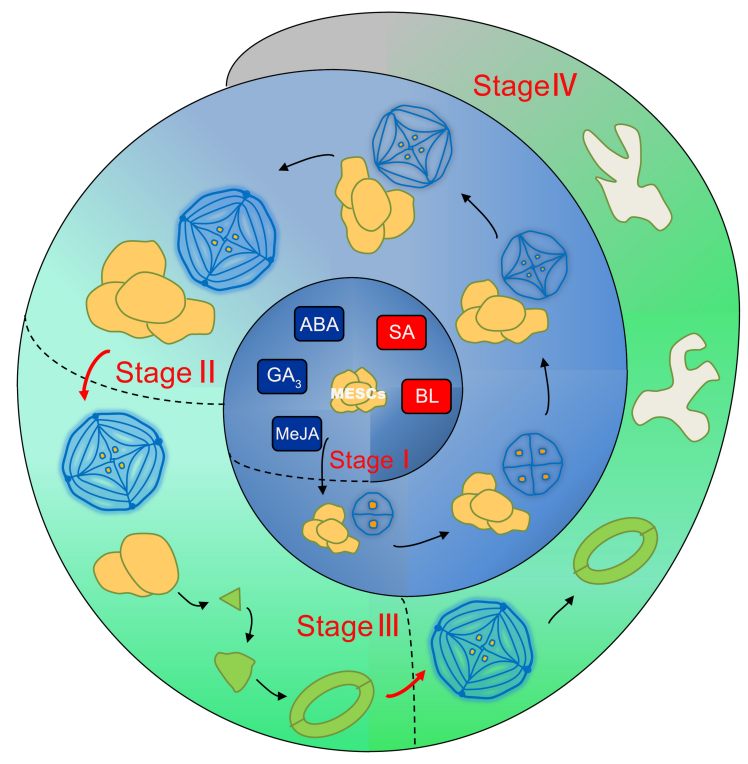

FIGURE 6 | The schematic model of coupled leaf development in L. bicolor. Four distinct stages are divided including stage I (MESCs undifferentiation stage), stage II (from MESCs to salt gland), stage III (from MESCs to stomata) and stage IV (from MESCs to pavement cell). In stage I, SA and BL promote the further differentiation of MESCs, while $\mathrm{GA}_{3}$, MeJA and ABA inhibit this process. In stage II, salt glands are formed through two-cell, four-cell, eight-cell, twelve-cell and sixteen-cell. Stomata emerged in stage III and pavement cells formed in stage IV.

previous studies of L. bicolor, salt gland number always showed a positive correlation with leaf area (Yuan et al., 2018); for example, $\mathrm{Ca}^{2+}$ treatment enhanced salt gland development and leaf expansion (Ding et al., 2010). Here, we observed strong and positive correlations between salt gland number and leaf area, indicating that salt gland development is coupled with leaf development.

\section{Total Salt Gland Number Versus Stomata Number}

Salt glands are not the only epidermal structure of $L$. bicolor. Stomata also responded to the different phytohormone treatments. The development of salt glands and stomata is thought to take place at distinct leaf developmental stages (Yuan et al., 2015). We obtained very strong, positive correlations between the numbers of salt glands and stomata, indicative of an indirect connection between salt gland and stomatal development. Moreover, we noted a positive correlation between stomatal number and pavement cell area, which was consistent with a previous study reporting that stomatal development is correlated with leaf area (Gay and Hurd, 2010).

Besides of the relationship between salt gland and pavement cell or stomata, there is an interesting phenomenon that no trichome distributed on the surface of L. bicolor. Given that trichomes also have the similar distribution pattern to salt gland, and trichomes from some species are reported to have secretory function (Wagner et al., 2004; Olsson et al., 2009), it is believed that there may be some homologous relationship between salt gland and trichome (Yuan et al., 2015). More will be verified by transformation the homologous genes involved in trichome development and salt gland development, such as a WD40-repeat protein (Yuan et al., 2019) and MYB transcription factor LbTRY (Leng et al., 2021).

Based on the former proposed salt gland development pattern (Yuan et al., 2015; Xu et al., 2020), we further improve the leaf development model (Figure 6) including MESCs (multipotent epidermal stem cells) stage, salt gland differentiation stage, stomata stage and pavement cell formation stage. The plant regulators proposed in the current report may directly act on the regulation of MESCs with promotion of SA and $\mathrm{BL}$, and inhibition of $\mathrm{GA}_{3}, \mathrm{MeJA}$ and $\mathrm{ABA}$ to further differentiate into different cell types. In conclusion, the leaf area of expanded leaves is a good direct indicator of the number of salt glands, stomata, and pavement cells. Salt glands on L. bicolor leaves can excrete excess $\mathrm{Na}^{+}$out of the plant to avoid salt overaccumulation, but their development is not disconnected from that of the rest of the leaf. Our present results revealed connections between the development of salt glands, stomata, and pavement cells, which will be benefit to the further study of salt glands development.

\section{DATA AVAILABILITY STATEMENT}

The raw data supporting the conclusions of this article will be made available by the authors, without undue reservation.

\section{AUTHOR CONTRIBUTIONS}

FY and MC designed the research. YG, BZ, and XJ performed the research. YG analyzed the data. YG and FY wrote the manuscript. FY and BW revised the manuscript. All authors contributed to the article and approved the submitted version.

\section{FUNDING}

This work was supported by the NSFC (National Natural Science Research Foundation of China, project nos. 31600200, 32170301 and 31770288), the MOE Layout Foundation of Humanities and Social Sciences (21YJAZH108), and the Shandong Provincial Bohai Granary Science and Technology Demonstration Project (2019BHLC004).

\section{SUPPLEMENTARY MATERIAL}

The Supplementary Material for this article can be found online at: https://www.frontiersin.org/articles/10.3389/fpls.2021. 745422/full\#supplementary-material

Supplementary Figure 1 | Salt gland density of the first true leaf under different hormone treatments. 


\section{REFERENCES}

Asami, T., Nakano, T., and Fujioka, S. (2005). Plant brassinosteroid hormones. Vitam Horm 72, 479-504. doi: 10.1016/S0083-6729(05)72014-8

Bao, F., Shen, J., Brady, S. R., Muday, G. K., Asami, T., and Yang, Z. (2004). Brassinosteroids Interact with Auxin to Promote Lateral Root Development in Arabidopsis. Plant Physiol. 134:1624. doi: 10.1104/pp.103.036897

Bazabakana, R., Fauconnier, M.-L., Diallo, B., Dupont, J., Homes, J., and El Jaziri, M. (1999). Control of Dioscorea alata microtuber dormancy and germination by jasmonic acid. Plant Growth Regulat. 27, 113-117. doi: 10.1023/ A:1006199432339

Breckle, S.-W. (1995). How do halophytes overcome salinity? Biol. Salt Toler. Plants 1995, 199-213.

Chen, R., Jiang, H., Li, L., Zhai, Q., Qi, L., Zhou, W., et al. (2012). The Arabidopsis mediator subunit MED25 differentially regulates jasmonate and abscisic acid signaling through interacting with the MYC2 and ABI5 transcription factors. Plant Cell 24, 2898-2916. doi: 10.1105/tpc.112.098277

Colebrook, E. H., Thomas, S. G., Phillips, A. L., and Hedden, P. (2014). The role of gibberellin signalling in plant responses to abiotic stress. J. Exp. Biol. 217, 67-75. doi: $10.1242 /$ jeb.089938

Dassanayake, M., and Larkin, J. C. (2017). Making Plants Break a Sweat: the Structure. Function, and Evolution of Plant Salt Glands. Front. Plant Sci. 8:406. doi: 10.3389/fpls.2017.00724

Daviere, J. M., and Achard, P. (2013). Gibberellin signaling in plants. Development 140, 1147-1151. doi: 10.1242/dev.087650

Ding, F. (2013). Effects of salinity and nitric oxide donor sodium nitroprusside (SNP) on development and salt secretion of salt glands of Limonium bicolor. Acta Physiol. Plant. 35, 741-747. doi: 10.1007/s11738-012-1114-8

Ding, F., Chen, M., Sui, N., and Wang, B. S. (2010). Ca2+ significantly enhanced development and salt-secretion rate of salt glands of Limonium bicolor under $\mathrm{NaCl}$ treatment. South Afr. J. Bot. 76, 95-101. doi: 10.1016/j.sajb.2009.09.001

Fan, C. (2020). Genetic mechanisms of salt stress responses in halophytes. Plant Signal Behav. 15:1704528. doi: 10.1080/15592324.2019.1704528

Feng, X., An, P., Li, X., Guo, K., Yang, C., and Liu, X. (2018). Spatiotemporal heterogeneity of soil water and salinity after establishment of dense-foliage Tamarix chinensis on coastal saline land. Ecolog. Eng. 121, 104-113. doi: 10. 1016/j.ecoleng.2017.06.031

Flowers, T. J., and Colmer, T. D. (2008). Salinity tolerance in halophytes. New Phytol. 179, 945-963. doi: 10.1111/j.1469-8137.2008.02531.x

Gay, A. P., and Hurd, R. G. J. N. P. (2010). The influence of light on stomatal density in the tomato. New Phytol. 75, 37-46. doi: 10.1111/j.1469-8137.1975.tb01368.x

Hasanuzzaman, M., Nahar, K., Alam, M. M., Bhowmik, P. C., Hossain, M. A., Rahman, M. M., et al. (2014). Potential Use of Halophytes to Remediate Saline Soils. BioMed. Res. Internat. 2014, 1-12. doi: 10.1155/2014/589341

Klessig, D. F., Choi, H. W., and Dempsey, D. A. (2018). Systemic Acquired Resistance and Salicylic Acid: Past, Present, and Future. Mol. Plant Microbe Interact. 31, 871-888. doi: 10.1094/MPMI-03-18-0067-CR

Lee, S., Kim, S. G., and Park, C. M. (2010). Salicylic acid promotes seed germination under high salinity by modulating antioxidant activity in Arabidopsis. New Phytol. 188, 626-637. doi: 10.1111/j.1469-8137.2010.03378.x

Leng, B. Y., Yuan, F., Dong, X. X., and Wang, B. S. (2018). Salt gland distribution in limonium bicolor at the individual level. IOP Conference Series: Earth and Environmental Science 113:012202 doi: 10.1088/1755-1315/113/1/012202

Leng, B., Wang, X., Yuan, F., Zhang, H., Lu, C., Chen, M., et al. (2021). Heterologous expression of the Limonium bicolor MYB transcription factor LbTRY in Arabidopsis thaliana increases salt sensitivity by modifying root hair development and osmotic homeostasis. Plant Sci. 302:110704. doi: 10.1016/j. plantsci.2020.110704

Li, G., Zhu, C., Gan, L., Ng, D., and Xia, K. (2014). GA3 enhances roo responsiveness to exogenous IAA by modulating auxin transport and signalling in Arabidopsis. Plant Cell Rep. 34, 483-494. doi: 10.1007/s00299-014-1728-y

Li, J., Pu, L., Han, M., Zhu, M., Zhang, R., and Xiang, Y. (2014). Soil salinization research in China: Advances and prospects. J. Geograph. Sci. 24, 943-960. doi: 10.1007/s11442-014-1130-2

Li, J., Yuan, F., Liu, Y., Zhang, M., Liu, Y., Zhao, Y., et al. (2020). Exogenous melatonin enhances salt secretion from salt glands by upregulating the expression of ion transporter and vesicle transport genes in Limonium bicolor. BMC Plant Biol. 20:493. doi: 10.1186/s12870-020-02703-x
Li, J., Zhao, C., Zhang, M., Yuan, F., and Chen, M. (2019). Exogenous melatonin improves seed germination in Limonium bicolor under salt stress. Plant Signal Behav. 14:1659705. doi: 10.1080/15592324.2019.1659705

Liu, J., Yang, R., Jian, N., Wei, L., Ye, L., Wang, R., et al. (2020). Putrescine metabolism modulates the biphasic effects of brassinosteroids on canola and Arabidopsis salt tolerance. Plant Cell Environ. 43, 1348-1359. doi: 10.1111/pce. 13757

Ma, X., Zheng, J., Zhang, X., Hu, Q., and Qian, R. (2017). Salicylic Acid Alleviates the Adverse Effects of Salt Stress on Dianthus superbus (Caryophyllaceae) by Activating Photosynthesis, Protecting Morphological Structure, and Enhancing the Antioxidant System. Front. Plant Sci. 8:600. doi: 10.3389/fpls.2017.00600

Meinke, and David, W. (1994). 10 Seed Development in Arabidopsis thaliana. Cold Spring Harbor Monograph Archive 1994:27.

Murashige, T., and Skoog, F. (1962). A revised medium for rapid growth and bioassays with tobacco tissue cultures. Physiol. Plant. 15, 473-497.

Olsson, M. E., Olofsson, L. M., Lindahl, A. L., Lundgren, A., Brodelius, M., and Brodelius, P. E. (2009). Localization of enzymes of artemisinin biosynthesis to the apical cells of glandular secretory trichomes of Artemisia annua L. Phytochemistry 70, 1123-1128. doi: 10.1016/j.phytochem.2009.07.009

Pan, W., You, Y., Shentu, J. L., Weng, Y. N., Wang, S. T., Xu, Q. R., et al. (2020). Abscisic acid (ABA)-importing transporter 1 (AIT1) contributes to the inhibition of $\mathrm{Cd}$ accumulation via exogenous ABA application in Arabidopsis. J. Hazard Mater. 391:122189. doi: 10.1016/j.jhazmat.2020.122189

Postiglione, A. E., and Muday, G. K. (2020). The Role of ROS Homeostasis in ABAInduced Guard Cell Signaling. Front. Plant Sci. 11:968. doi: 10.3389/fpls.2020. 00968

Qiu, Z., Guo, J., Zhu, A., Zhang, L., and Zhang, M. (2014). Exogenous jasmonic acid can enhance tolerance of wheat seedlings to salt stress. Ecotoxicol. Environ. Saf. 104, 202-208. doi: 10.1016/j.ecoenv.2014.03.014

Rajjou, L., Belghazi, M., Huguet, R., Robin, C., Moreau, A., Job, C., et al. (2006) Proteomic Investigation of the Effect of Salicylic Acid on Arabidopsis Seed Germination and Establishment of Early Defense Mechanisms. Plant Physiol. 141, 910-923. doi: 10.1104/pp.106.082057

Rengasamy, P. (2006). World salinization with emphasis on Australia. J. Exp. Bot. 57, 1017-1023. doi: 10.1093/jxb/erj108

Rivas-San Vicente, M., and Plasencia, J. (2011). Salicylic acid beyond defence: its role in plant growth and development. J. Exp. Bot. 62, 3321-3338. doi: 10.1093/ jxb/err031

Rozema, J., and Flowers, T. (2008). Ecology. Crops for a salinized world. Science 322, 1478-1480. doi: 10.1126/science. 1168572

Rozema, J., and Riphagen, I. (1977). Physiology and ecologic relevance of salt secretion by the salt gland of Glaux maritima L. Oecologia 29, 349-357. doi: 10.1007/BF00345808

Ruan, C.-J., Da Silva, J. A. T., Mopper, S., Qin, P., and Lutts, S. (2010). Halophyte Improvement for a Salinized World. Crit. Rev. Plant Sci. 29, 329-359. doi: 10.1080/07352689.2010.524517

Shabala, S. (2013). Learning from halophytes: physiological basis and strategies to improve abiotic stress tolerance in crops. Ann. Bot. 112, 1209-1221. doi: $10.1093 / \mathrm{aob} / \mathrm{mct} 205$

Shi, T. Q., Peng, H., Zeng, S. Y., Ji, R. Y., Shi, K., Huang, H., et al. (2017). Microbial production of plant hormones: Opportunities and challenges. Bioengineered 8, 124-128. doi: 10.1080/21655979.2016.1212138

Thomson, W. W. (1975). "The structure and function of salt glands," in Plants Saline Environments, Vol. 15, eds A. Poljakoff-Mayber, J. Gale (Berlin: Springer), 118-146.

Verma, V., Ravindran, P., and Kumar, P. P. (2016). Plant hormone-mediated regulation of stress responses. BMC Plant Biol. 16:86. doi: 10.1186/s12870-0160771-y

Vogler, F., Schmalzl, C., Englhart, M., Bircheneder, M., and Sprunck, S. (2014) Brassinosteroids promote Arabidopsis pollen germination and growth. Plant Reprod 27, 153-167. doi: 10.1007/s00497-014-0247-x

Wagner, G. J., Wang, E., and Shepherd, R. W. (2004). New Approaches for Studying and Exploiting an Old Protuberance, the Plant Trichome. Ann. Bot. 93, 3-11. doi: 10.1093/aob/mch011

Wiehe, W., and Breckle, S. W. (1990). Die Ontogenese der Salzdrüsen von Limonium (Plumbaginaceae); The Ontogenesis of the Salt Glands of Limonium (Plumbaginaceae). Botanica Acta 103, 107-110. doi: 10.1111/j.1438-8677.1990. tb00135.x 
Wu, W., Zhang, Q., Ervin, E. H., Yang, Z., and Zhang, X. (2017). Physiological Mechanism of Enhancing Salt Stress Tolerance of Perennial Ryegrass by 24-Epibrassinolide. Front. Plant Sci. 2017:8. doi: $10.3389 /$ fpls.2017.01017

Xu, Y., Jiao, X., Wang, X., Zhang, H., Wang, B., and Yuan, F. (2020). Importin$\beta$ From the Recretohalophyte Limonium bicolor Enhances Salt Tolerance in Arabidopsis thaliana by Reducing Root Hair Development and Abscisic Acid Sensitivity. Front. Plant Sci. 11:582459. doi: 10.3389/fpls.2020.582459

Yu, Z., Duan, X., Luo, L., Dai, S., Ding, Z., and Xia, G. (2020). How Plant Hormones Mediate Salt Stress Responses. Trends Plant Sci. 25, 1117-1130. doi: 10.1016/j. tplants.2020.06.008

Yuan, F., and Wang, B. (2020). Adaptation of Recretohalophytes to Salinity. Handbook Halophytes 2020, 1-21. doi: 10.1007/978-3-03017854-3_32-1

Yuan, F., Chen, M., Yang, J., Leng, B., and Wang, B. (2014). A system for the transformation and regeneration of the recretohalophyte Limonium bicolor. Vitro Cell. Dev. Biol. Plant 50, 610-617. doi: 10.1007/s11627-014-9611-7

Yuan, F., Leng, B., and Wang, B. (2016a). Progress in Studying Salt Secretion from the Salt Glands in Recretohalophytes: How Do Plants Secrete Salt? Front. Plant Sci. 7:977. doi: 10.3389/fpls.2016.00977

Yuan, F., Lyu, M.-J. A., Leng, B.-Y., Zhu, X.-G., and Wang, B.-S. (2016b). The transcriptome of $\mathrm{NaCl}$-treated Limonium bicolor leaves reveals the genes controlling salt secretion of salt gland. Plant Mole. Biol. 91, 241-256. doi: 10.1007/s11103-016-0460-0

Yuan, F., Leng, B., Zhang, H., Wang, X., Han, G., and Wang, B. (2019). A WD40-Repeat Protein From the Recretohalophyte Limonium bicolor Enhances
Trichome Formation and Salt Tolerance in Arabidopsis. Front. Plant Sci. 10:1456. doi: 10.3389/fpls.2019.01456

Yuan, F., Liang, X., Li, Y., Yin, S., and Wang, B. (2018). Methyl jasmonate improves tolerance to high salt stress in the recretohalophyte Limonium bicolor. Funct. Plant Biol. 46, 82-92. doi: 10.1071/FP18120

Yuan, F., Lyu, M. J., Leng, B. Y., Zheng, G. Y., Feng, Z. T., Li, P. H., et al. (2015). Comparative transcriptome analysis of developmental stages of the Limonium bicolor leaf generates insights into salt gland differentiation. Plant Cell Environ. 38, 1637-1657. doi: 10.1111/pce.12514

Conflict of Interest: The authors declare that the research was conducted in the absence of any commercial or financial relationships that could be construed as a potential conflict of interest.

Publisher's Note: All claims expressed in this article are solely those of the authors and do not necessarily represent those of their affiliated organizations, or those of the publisher, the editors and the reviewers. Any product that may be evaluated in this article, or claim that may be made by its manufacturer, is not guaranteed or endorsed by the publisher.

Copyright (c) 2021 Gao, Zhao, Jiao, Chen, Wang and Yuan. This is an open-access article distributed under the terms of the Creative Commons Attribution License (CC BY). The use, distribution or reproduction in other forums is permitted, provided the original author(s) and the copyright owner(s) are credited and that the original publication in this journal is cited, in accordance with accepted academic practice. No use, distribution or reproduction is permitted which does not comply with these terms. 